\title{
CORRIGENDUM
}

\section{Effects of eprinomectin on the survival, reproduction and feeding activity of the dung beetles, Onthophagus lenzii Harold, and rare species, Copris ochus Motschulsky (Coleoptera: Scarabaeidae) - CORRIGENDUM}

\author{
I. Ishikawa and M. Iwasa \\ doi.org/10.1017/S0007485318000317 Published online by Cambridge University Press, 22 May 2018
}

In the recent publication mentioned above, the authors would like to apologise for making an error in the conversion of the values of the vertical axis in Figure 1 that is now featured in the final version of the article. The corrected figure is below.

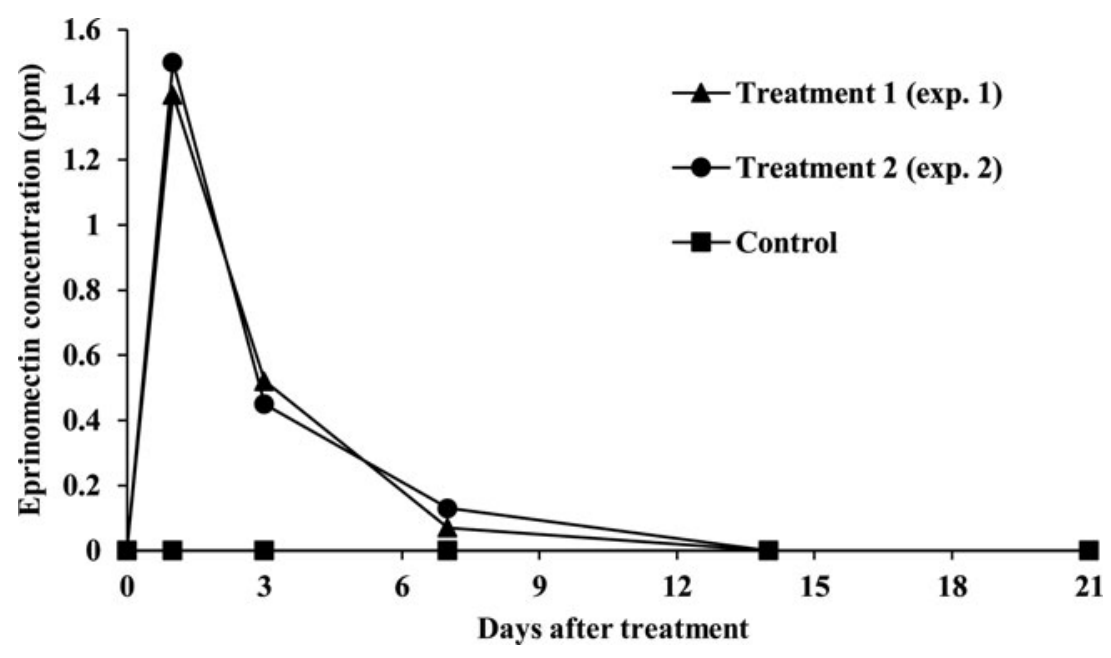

\section{Reference}

Ishikawa, I. and Iwasa, M. (2018) "Effects of eprinomectin on the survival, reproduction and feeding activity of the dung beetles, Onthophagus lenzii Harold, and rare species, Copris ochus Motschulsky (Coleoptera: Scarabaeidae)," Bulletin of Entomological Research. Cambridge University Press, pp. 1-8. doi: 10.1017/S0007485318000317. 